other hund, cow's milk is not sweet cnough, and when eompared with human milk very indignestible. It ean only be made at all a possible food for babies by alding to it sugar and water and so making it more like condensed milk, but even then it is not so digestible as condensed milk; and it is not diflicult to sce the reason. Place somo cow's milk with its added sugar and water in $a$ winoglass mix in anotber glass some condensed milk with water till it has, as far as one can judge by eye, about the same consistence and opaaity; stand the two glaskes side by side, and add to e ich, as the stomach does, a few drops of dilute nitro-hydrochloric acid and watch the result. They both curdle, hut the curd formed in the wineglass of condensed milk is distinctly more fiable, more mixed with the watery part than the curd in the cow's milk, and after standing for some time this is still more evident, for the curd in the fresh milk separates completely from the fluid into a firm clot, while in the condensed milk it remains more granular, more broken up, and more mixed with the fluid. And, except among the very poor, who cannot afford to buy cow's milk, it is this hard clot of cow's milk which is more than anything else the fons ct origo of that only too well-known incessant cry of dyspeptic hand-fed babies, and of all the vomiting and diarrhoea which so often carry them offthat hard indigestible clot, of which there is so little in buman milk, and of which the avalytical reports say with precise truth, as they might of a dinner of cheese, that it is so "nutritious," so full of "nitrogenous matter." And it is actually because of the small proportion of clot or casein which condensed milk contains that the second objection to it is made by the analysts. This clot or casein, which is so much the bane of hand-fed infants that the addition of oatmeal-water or gruel to cow's milk, even before the child is able to digest any starchy food at all, often makes the milk more digestible, for the simple reason that the suspended particles in the oatmeal-water are interspersed through the coagulum which is formed when the milk enters the stomach, and so help to make it soft and friable, just as water-weeds frozen into ice make the ice brittle and dangerous to skate on.

Condensed milk, of course, varies in quality, and it is important not to use any of the common cheap kinds. Of those which are generally seen in the shop windows, the outpatient mothers at our children's hospitals generally prefer the original Anglo-Swiss milk, the "one with the milkmaid on the tin," as they call it, and it seems to me as good as any. And lately some unsweetened Swiss milk has been prepared, which has the appearance of being good, and certainly deserves a trial.

Then as to condensed milk causing rickets, I can only say that I have found it very difficult to trace rickets to condensed nilk properly given. Most hand-fed children are delicate, a very large proportion die, and a still larger proportion have some tendency to rickets. Oatmeal and other gruels seem to be directly concerned in bringing it about; but though I bave seen very many children who have had to change their diet to condensed milk, I have seen none who have thereupon become rickety. One case I do remember among the out-patients at the Victoria Hospital for Children of a child a year old who had advanced rickets. It had been fed on condensed milk, the mother said, from birth, and yet it had never thriven. She had done her best for the child; the milk was of the best brand, and she never spared it. She spread it thick on slices of bread, and gave it to the child whenever it cried, "And yet," the poor woman said, "the child doesn't get on." That condensed milk given in that form to habies, even without the bread, may cause rickets I to not attempt to deny. It appears to me to be rather to the credit of condensed milk that the baby survived.

Everything depends upon how condensed milk is given. It ought to be diluted with ten or twelve times its bulk of water, or with more than that if the child is thirsty; and if any tendency to sickness remains, about one-sixth of the water ought to be lime-water, which still further neutralizes the action of the acid of the stomach and delays the formation of the clot. The water should be boiling when added to the milk, especially in the summer. It gets rid of the infusoria in bad water or in a longr-opened tin. Once a day a teaspoonful of Mellin's food may be given with the milk. It is one of the best of the semi-digested foods, and children like it. With such a diet infants who at once vomit cow's milk, who keep their knees drawn up in pain, who are wasted and wretched looking, or in danger of dying from diarrhora, become contented and happy, rapidly gain flesb and are able after a time to begin a little weak cow's mill and witer or whey. $\Lambda$ nd it is thus as a bridge across a bad time that I consider condensed milk to be of the greatest importance; but the bridge may extend over some months and in the mean time the irritability of the intestinal tract subsides, and other forms of nourishment can be gradually arlministered.

Three or four years ago when I was a resident medical officer at the Children's Hospital in Great Ormond-street where good cow's milk could always be procured, and where it was given with care and discretion, condensed milk formed nevertheless a valuable article of diet, and was and probably is still used in all the medical wards; but among the poo in their own homes, where the milk is often bad throughont the year, and sour for at least three months of it, condensed milk is simply an inestimable boon.

Brook-street, $\mathrm{W}$.

\section{AN OPERATION FOR THE RADICAL CURE OF FEMORAL HERNIA.}

BY WALTER H. BROWN, M.R.C.S.,

SURGEON TO THE LEEDS PUBLIC DISPENSARY; DEMONSTRATOR OP ANATOMY, LEEDS SCHOOL OF MEDICINE; LATE HOUSE-SURGEON, LEEDS GENERAL INFIRMARY.

A FEMLLE, aged sixty, had for years been troubled with a large femoral hernia. Many varieties of truss had been tried, but all failed to afford relief, and the hernia had been strangulated two or three times for short periods. For reasons which I will give below I deemed it desirable to make an attempt to effect a radical cure, to which end I performed the following operation.

I made an incision as for strangulated bowel, and opened the sac. I reduced the bowel, and then found that the crural ring was large enough to admit three fingers; lying at the posterior part of the sac was a large portion of omentum, which was adherent to the sac, and, as in separating these adhesions the omentum was freely handled, I removed the portion which had been in the sac, and tied the stump with a stout silk ligature, leaving the end of the ligature long. I then dissected out the sac, and, after ligaturing the neck, removed the entire sac. I had next a large piece of omentum removed by a ligature within the abdominal cavity just opposite the crural ring, the ligature being brought out through a small opening I had made in the peritoneum close to the ligatured neck of the sac. It now occurred to me that I might use this omentum as a plug to close the crural ring. I therefore drew the omentum down until it was in contact with the neck of the sac, and found that it remained in its new position without much tension. I thus had the ligatured neck of the sac and the ligatured stump of the omentum to resist the return of the hernia. The wound was closed in the ordinary way, the two silk ligatures being brought out at the lower end.

It is unnecessary to give further details of the progress of the case as the woman made a good recovery. There was no disturbance of temperature, the wound healed by first intention save at the point through which the ligatures came; the ligature on the neck of the sac came away on the tenth day, but the one on the omentum remaining firm at the end of the sixteenth day, it was cut short and the wound healed in two days.

The operation was performed in accordance with Professor Lister's system of antiseptics, and the wound dressed with salicylic silk as introduced by Mr. McGill of Leeds. It is now five months since the operation, and the result so far has been perfectly satisfactory. There is no hernia, the woman is enabled to perform her household and other duties in comfort; she wears a pad similar to that of an ordinary truss over the scar in order to support the necessarily weak ring. I am fully aware that an operation such as I have deseribed is open to criticism, and I therefore wish before closing to draw attention to my reasons for operating. First, the patient being weary and discomfited by her ailment was willing to accept the risks of operation and possible failure after they had been fully explained. Secondly, a fair trial had been given to mechanical support, and the results had been entirely unsuccessful. Thirdl5, 1 deemed it right to at+empt a cure by operation, bearing in mind the fact that' of late we have been in the habit of 
dealing more freely with cases which involve interference with the peritoneum. The brilliant results obtained by Mr. Banks of Liverpool, and Mr. Spanton of Hanley, in dealing with inguinal hernix, led me to undertake the operation just described, and Mr. Spencer of York has performed a similar operation with like success.

Of course the number of cases in which one would operate would be limited to those in which mechanical support had failed to give relief.

Leeds.

\section{COMPLETE SUPPRESSION OF SALIVA AFTER MUMPS.}

\section{BY A. ST. C. BUXTON.}

COMPLETE suppression of saliva in both parotids and both submaxillaries is of extremely rare occurrence. A case has, however, quite recently come under my care, the features of which were as follows.

A lady of over middle age, while in the country, contracted mumps. As soon as the acute inflammation of the salivary glands had subsided, and all pain and swelling had disappeared, she returned to town, and I was called in to see her. She spoke with great difficulty, and was forced to sip water at very short intervals in order to be able to speak at all. She told me that ever since the pain in the parotids and and submaxillaries had vanished her mouth had remained persistently quite dry.

On examination I found her tongue, gums, cheeks, palate, and pharynx - in fact as much as it was possible to see of the mouth and throat-in a fearfully dried up state. The tongue was thickly coated with a tough brown fur, which was horn-like. So hard was it that on striking it gently with a metal probe a distinct sound as of tapping the cover of a book with a cedar pencil was produced. The rest of the interior of the mouth was also extremely hard, and she experienced great stiffness in opening and closing the jaws. No swelling or tenderness on pressure existed about the salivary glands, and the orifices of Stenson's and Wharton's ducts were plainly seen. It is needless to say that she retained no sense of taste. She complained of the heat felt in the mouth, but the temperature was quite normal. Her sleep was greatly disturbed at night, and she awoke at short intervals with the most intense longing for cold water ; but drinking afforded no relief. It is worthy of notice that for some three or four years she has been affected with paralysis agitans, both limbs of the right side being very shaky. She enjoys otherwise excellent general health, and, notwithstanding the trembling in the right leg, is able to walk well, and takes plenty of exercise out of doors. There was a great deal of difficulty in feeding her, for she abso. lutely refused milk and beef-tea, and the effort necessary to swallow jelly and other semi-solid food was very great. I prescribed gargles of potassic chlorate, and ordered glycerine to be applied locally to the interior of the mouth and surface of the tongue. I ordered also an infusion of lifty grains of jaborandi to be taken daily for four days. Although the glycerine afforded some slight relief to the mouth by its mechanical effect as a lubricator, there was positively no effect produced on the salivary glands. Copious perspiration (from the jaborandi) took place, and left her feeling very weak. I therefore abandoned that drug, and substituted mercuric iodide dissolved in excess of potassic iodide. I gave large doses for ten days with no result beyond the production of a feeling of malaise. It was evident that something must be done soon to excite the flow of saliva, for the patient had been in this condition for nearly three weeks, and was in the lowest depths of despair and misery. The next step which I took therefore was the application of a continuous current of electricity generated by a 30-cell battery (pint cells) of the Leclanché type. I introduced a very fine silver probe into Stenson's duct on one side, and pushed it gently on until I met with obstinate resistance to further entrance. The probe had then entered the duct about an inch. My assistant held the positive electrode firmly to the nape of the neck, while I cautiously applied the negative pole to the free end of the probe. I instantly noticed a contraction of the fibres of the buccinator, but as no pain resulted I fixed the wire to the probe and allowed the passage of the current to continue for ten minutes. While the probe was in the duet a thick white liquid oozed from the orifice. It looked something like pus. On removal of the probe a single drop of clear saliva followed it. Thinking that it was just within the bounds of possibility that small abscess had existed somewhere about the duct and had been overlooked, and the probe had simply opened it and so cleared the obstruction to the flow of saliva into the mouth, I determined to thoroughly explore the other Stenson's duct and both Wharton's ducts before applying the current again. I passed the probe into all three remaining ducts as far as possible, removed it, compressed and squeezed the parts, but no pus followed. I repeated this again, but without finding a trace of pus. I then applied the current as before, with precisely the same result as in the first instance. I had the satisfaction of seeing four drops of saliva, one at the orifice of each duct. I visited my patient an hour afterwards, and a gentle flow of saliva was discernible from each duct. For three days the quantity steadily increased, without any further use of the current, and at the end of that time almost the normal amount was being poured out. The mucous membrane lining the mouth and the tongue was rapidly resuming its natural appearance. I have not seen my patient since, but I received a letter two days later stating that she had greatly improved; that the tongue was feeling quite comfortable, and that she was able to taste. A somewhat similar case is mentioned in the London Medical Record, 1877. The suppression of saliva resulted on that occasion from tonsillitis, and the flow was restored by stimulation by continuous current "frequently reversed." I did not reverse my current, preferring to submit the glands to the continued action of the negative pole. I find no mention of the condition in any medical work in which $I$ have searched, includ. ing Quain's Dictionary. of Medicine.

The Grove, W.

\section{ON A CASE OF}

\section{LABIO-GLOSSO-PHARYNGEAL PARALYSIS OCCURRING AT THE AGE OF} TWENTY-THREE YEARS.

\section{BY A. CHAMPNEYS CLARKE, L.K. Q.C.P.I., \&c.}

ON Nov. 13th, 1882, I was sent for to see Mrs. B-C, aged twenty-three years, wife of a coal miner. I was informed that she had always enjoyed good health, had borne one healthy child, and was now six months advanced in pregnancy. The previous evening, while shoveling coals into the coal-house, standing at the time in the snow, she had been seized with what was described as a sort of stroke. I found her suffering from paralysis of the left side of the face and left arm; articulation was imperfect owing to paralysis of the left half of the tongue, which when protruded was drawn towards the right side of the mouth. She gradually recovered from the facial paralysis, and in a great measure the use of her left arm, only complaining of its being weak. On February 11th I was again sent for to see Mrs. B she was said to have had another stroke. On arrival I found she had just been delivered of a healthy child, after a short and easy labour. She was completely unable to articulate or swallow, the tongue lay immovable on the floor of the mouth behind the teeth, hollowed in the centre; she could not close her lips completely, and the saliva dribbled from the sides of the mouth. The patient, an intelligent woman, complained (by signs) of great pain in the neck and throat, the muscles of which were contracted. She was at first fed through a tube, but disliking this means she was spoon fed, the spoon being introduced well back. She made a rapid convalescence from her confinement, and at the end of a week could swallow with considerable difficulty, placing the food (oruel and beef-tea) well back in her mouth and throwing the head back. The stiffness passed off, and she can now (March 21st) take fluid and semi-solid food fairly well. She is able to go about her household duties, but the tongue still remains paralysed, though by a great effort she can raise it as far as the edges of the teeth. She can close the lips at will, but when not called upon to do so the mouth hangs open and the saliva dribbles from the edges. She cannot articulate a single word, nor any letter in which the tongue has to be used.

The points of interest in this case are, I believe, the hitherto unknown occurrence of glosso-pharyngeal paralysis at so early 